\title{
Seletividade do ethoxysulfuron às culturas da soja e feijão ${ }^{1}$
}

\author{
Selectivity of ethoxysulfuron to soybean and common bean
}

Ana Caroline de Lourdes Pereira Assis ${ }^{2}$; Marcelo Rodrigues dos Reis ${ }^{3}$; Gabriella Daier Oliveira Pessoa $^{4}$; Daniel Valadão Silva ${ }^{5}$; Marcos Hayata ${ }^{2}$ Roque Carvalho Dias ${ }^{2}$; Bruno Henrique Rocha ${ }^{6}$

Resumo - A emergência da soja durante o cultivo do feijão pode interferir negativamente na produtividade do feijoeiro. Este problema pode ser minimizado com o uso de herbicida que seja seletivo ao feijoeiro e não seletivo a soja. Neste contexto, avaliou-se a seletividade do herbicida ethoxysulfuron às culturas da soja e do feijão. Dois experimentos foram realizados em casa de vegetação no delineamento de blocos casualizados, com quatro repetições. Cada experimento correspondeu a uma cultura avaliada: feijão ou soja. Os tratamentos foram arranjados em esquema fatorial $2 \times 9$, com o primeiro fator correspondente a aplicação do herbicida isolado ou em mistura com óleo mineral Nimbus ${ }^{\circledR}$ na concentração de $0,5 \% \mathrm{v} / \mathrm{v}$ e o segundo fator das doses do ethoxysulfuron $\left(0 ; 1,8 ; 3,6 ; 5,4 ; 7,2 ; 9,0 ; 13,5 ; 18,0\right.$ e 36,0 $\left.\mathrm{g} \mathrm{i.a} \mathrm{ha}^{-1}\right)$. Avaliou-se aos 7, 14, 21 e 28 dias após a aplicação do herbicida (DAA) a fitointoxicação visual e aos 35 DAA a área foliar e massa da matéria seca total das plantas. $O$ ethoxysulfuron causou baixa intoxicação às plantas de feijão, sem interferir na área foliar e na massa da matéria seca total das plantas. A soja foi sensível ao herbicida, sobretudo nas maiores doses e na presença do óleo mineral. A dose de $36 \mathrm{~g}$ i.a. ha ${ }^{-1}$ de ethoxysulfuron com o óleo mineral causou a morte das plantas de soja, sem alterar o crescimento do feijoeiro.

Palavras-chaves: Phaseolus vulgaris, Glycine max, planta voluntária, tiguera

\begin{abstract}
The emergence of soybean seeds in fields during the common bean cultivation can negatively affect the growth and yield of this crop. This problem can be minimized with the use of selective herbicides to common bean but non-selective to soybean. Aiming to define management strategies to voluntary soybean plants in the common beans crop, this research was carried out to evaluate the selectivity of ethoxysulfuron to soybean and common beans crops. Two experiments were conducted in a greenhouse, in randomized block design with four replications. Each experiment corresponded to a crop: soybean or common bean. Treatments were arranged in factorial arrangement $2 \times 9$, where the first factor corresponds to herbicide application single or in tank mixture with mineral oil Nimbus ${ }^{\circledR}$ at $0.5 \% \mathrm{v} / \mathrm{v}$ and the second was related to ethoxysulfuron doses $\left(0,1.8,3.6,5.4,7.2,9.0,13.5,18\right.$ and $36 \mathrm{~g}$ a.i. $\left.\mathrm{ha}^{-1}\right)$. At 7, 14, 21, and 28 days after application (DAA) was evaluated the visual intoxication, and at 35 DAA the leaf area and total plant dry matter. The ethoxysulfuron caused low intoxication to common bean plants, without interfering in leaf

\footnotetext{
${ }^{1}$ Recebido para publicação em 19/08/2014 e aceito em 02/07/2015.

2 Discente do Curso de Agronomia - Universidade Federal de Viçosa. Rio Paranaíba, MG, Brasil. Email: ana_pereira_assis@ hotmail.com (*autor para correspondência)

${ }^{3}$ Docente do Departamento de Ciências Agrárias - Universidade Federal de Viçosa. Rio Paranaíba, MG, Brasil.

${ }^{4}$ Discente do Programa de Pós-graduação em Agronomia - Universidade Federal de Viçosa. Rio Paranaíba, MG, Brasil.

${ }^{5}$ Docente do Departamento de Ciências Vegetais - Universidade Federal Rural do Semi-Árido. Mossoró, RN, Brasil.

${ }^{6}$ Técnico Agrícola- Universidade Federal de Viçosa. Rio Paranaíba, MG, Brasil.
} 
area and total plant dry matter. Soybean was sensitive to this herbicide, especially in higher doses and in the presence of mineral oil. The dose of $36 \mathrm{~g}$ a.i. $\mathrm{ha}^{-1}$ of ethoxysulfuron plus mineral oil caused the death of soybean plants without interfere in growing of common bean crop.

Keywords: Phaseolus vulgaris, Glycine max, voluntary plants, volunteer soybean

\section{Introdução}

O feijão (Phaseolus vulgaris L.) é uma leguminosa de grande importância na alimentação humana. O Brasil é o maior produtor mundial de feijão, com uma produção estimada de 3,56 milhões de toneladas em 2014, sendo o feijoeiro cultivado por pequenos e grandes produtores durante todo o ano e em todas as regiões brasileiras (IBGE, 2014).

A interferência promovida pelas plantas daninhas destaca-se entre as causas do baixo rendimento do feijoeiro (Cobucci et al., 1999; Kozlowski et al. 2002; Teixeira et al., 2009; Borchartt et al., 2011). De maneira geral, para obtenção de máximas produtividades, o feijoeiro deve estar livre de competição com plantas daninhas nas primeiras semanas de cultivo (Kozlowski et al., 2002; Borchartt et al., 2011). Desta maneira, medidas de controle devem ser adotadas visando impedir o convívio da cultura com as plantas daninhas.

No Brasil, o feijoeiro tem sido frequentemente cultivado em sucessão com a cultura da soja. Todavia, devido à deiscência natural da vagem ou a incorreta regulagem da colhedora, têm-se observado no campo elevadas perdas de grãos de soja e, consequentemente, a emergência de plantas de soja na lavoura de feijão torna a primeira uma planta daninha. Entretanto, existem poucas alternativas de controle químico da soja em cultivos do feijoeiro, devido à semelhança morfológica que essas plantas apresentam e pelo fato de pertencerem à mesma família.

O ethoxysulfuron é um ingrediente ativo do grupo das sulfoniluréias e atua inibindo a ação da enzima acetolactatosintase (ALS) paralisando a síntese dos aminoácidos isoleucina, leucina e valina (Silva et al., 2007). O sintoma típico deste grupo de herbicida em plantas é o amarelecimento das partes mais jovens da planta. Inicialmente, as folhas jovens tornam-se cloróticas, murcham, necrosam e morrem; estes efeitos são difundidos para o restante da planta, devido à ação sistêmica do herbicida com translocação pelo xilema e floema, na etapa seguinte poderá aparecer pigmentos vermelhos ou roxos, principalmente nas nervuras da face abaxial das folhas (Leite et al., 1998).

A hipótese deste trabalho é que exista diferença na tolerância entre as culturas do feijão e da soja ao ethoxysulfuron aplicado em pós-emergência. Todavia, esse diferencial pode ser dependente da dose aplicada do herbicida e da adição de adjuvantes. Visando definir estratégias de manejo de plantas voluntárias de soja na cultura do feijão, realizou-se esse trabalho com o objetivo de avaliar a seletividade do ethoxysulfuron às culturas da soja e do feijão.

\section{Material e Métodos}

Foram realizados dois experimentos em casa de vegetação pertencente à Universidade Federal de Viçosa, Rio Paranaíba - MG, durante o período de maio a julho de 2014. Utilizou-se como substrato um Latossolo Vermelho distroférrico, textura argilosa, coletado em uma profundidade de $0-10 \mathrm{~cm}$ que, após secagem ao ar, foi peneirado (malha de cinco $\mathrm{mm}$ ). As características químicas e granulométricas do solo estão descritas na Tabela 1. A adubação de plantio foi realizada com o uso de 1,4 g de MAP, 2,3 g de supersimples, $1,2 \mathrm{~g}$ de trimag e $0,1 \mathrm{~g}$ de cloreto de potássio por $\mathrm{dm}^{3}$ de solo.

Os dois experimentos foram realizados no delineamento em blocos casualizados, com quatro repetições. Cada experimento correspondeu a uma cultura avaliada: soja ou feijão. Os tratamentos foram arranjados em esquema fatorial $2 \times 9$, sendo o primeiro fator correspondente da aplicação do herbicida 
isolado ou em mistura com óleo mineral Nimbus ${ }^{\circledR}$ na concentração de $0,5 \%$ v/v e o segundo fator refere às doses do ethoxysulfuron
$(0 ; 1,8 ; 3,6 ; 5,4 ; 7,2 ; 9,0 ; 13,5 ; 18$ e 36 g i.a ha${ }^{1}$ ) aplicados em pós-emergência do feijão e da soja.

Tabela 1 - Características físico-químicas da amostra de Latossolo Vermelho distroférrico, textura argilosa, utilizada no experimento. Rio Paranaíba - MG, 2013.

\begin{tabular}{|c|c|c|c|c|c|c|}
\hline$\frac{\mathrm{pH}}{\left(\mathrm{H}_{2} \mathrm{O}\right)}$ & & $\mathrm{Al}^{3+}$ & $\mathrm{H}^{+}+\mathrm{Al}^{3+}$ & $\begin{array}{l}\mathrm{Ca}^{2+}+\mathrm{Mg}^{2+} \\
\left.\mathrm{ll}_{\mathrm{c}} \mathrm{dm}^{-3}\right)\end{array}$ & $\mathrm{Ca}^{2+}$ & $\mathrm{K}^{+}$ \\
\hline 6,00 & & 0,00 & 3,50 & 4,60 & 3,60 & 1,00 \\
\hline $\begin{array}{c}\text { M.O. } \\
\left(\operatorname{dag}^{-3} \mathrm{dm}^{-3}\right)\end{array}$ & $\begin{array}{c}\mathrm{P} \\
\left(\mathrm{modm}^{-3}\right)^{-3}\end{array}$ & $\begin{array}{c}\text { CTC } \\
\left(\mathrm{cmol}^{-3} \mathrm{dm}^{-3}\right)\end{array}$ & ${ }^{\mathrm{V}}$ & Areia & $\begin{array}{c}\text { Silte } \\
\left(\mathrm{dag}_{\mathrm{kg}} \mathrm{g}^{-1}\right.\end{array}$ & Argila \\
\hline 2,40 & 13,90 & 8,37 & 58,00 & 32,90 & 11,70 & 55,40 \\
\hline
\end{tabular}

Cada unidade experimental correspondeu à um vaso de $8,0 \mathrm{dm}^{3}$ preenchidos com solo. Foram semeadas cinco sementes de cultura avaliada, realizando-se, aos cinco dias após a emergência, o desbaste das plantas visando estabelecer duas plantas da cultura teste por vaso.

A aplicação do herbicida foi realizada quando as plantas se encontravam no estádio $\mathrm{V}_{3}$ da soja Roundup Ready ${ }^{\circledR}$ e do feijão tipo Carioca. Utilizou-se um para isso um pulverizador costal pressurizado a $\mathrm{CO}_{2}$, operando à pressão constante de $3,0 \mathrm{kgf} \mathrm{cm}^{-2}$, equipado com barra de duas pontas TT 110.02 espaçadas de $50 \mathrm{~cm}$, a uma altura de $50 \mathrm{~cm}$ do alvo, e volume de calda equivalente a $150 \mathrm{~L} \mathrm{ha}^{-}$ 1 .

Aos 7, 14, 21 e 28 dias após a aplicação do herbicida avaliou-se a fitointoxicação das plantas de feijão e soja através de escala de notas na qual $0 \%$ representa nenhuma injúria e $100 \%$ morte das plantas, conforme a metodologia da SBCPD (1995).

Aos 35 dias após a aplicação determinou-se a área foliar das culturas. Além disso, todo o material vegetal foi colhido e, posteriormente, seco em estufa com circulação forçada de ar, a $65{ }^{\circ} \mathrm{C}$, até atingir peso constante para determinação da massa da matéria seca total (raízes e parte aérea).

Os dados foram submetidos à análise de variância pelo teste $\mathrm{F}(\mathrm{P}<0,05)$ e análise de regressão. As escolhas do modelo de regressão foram baseadas na significância dos coeficientes, no coeficiente de determinação e no comportamento biológico do fenômeno.

\section{Resultados e Discussão}

A aplicação do ethoxysulfuron provocou baixos sintomas de fitointoxicação no feijoeiro em todas as avaliações realizadas (Figura 1). As plantas apresentavam pontos cloróticos nas folhas mais novas, e esses sintomas eram potencializados na medida em que se aumentava a dose. Aos 7 dias após a aplicação do herbicida (DAA) constatou-se aumento linear da fitointoxicação causada pelo produto com a adição do óleo mineral, enquanto que isoladamente o ethoxysulfuron, causou notas próximas a $12 \%$, porém estabilizando nas maiores doses. Nas avaliações aos 14 e 21 DAA, notou-se aumento linear da fitointoxicação, independente do uso ou não do óleo mineral. No entanto, aos 28 DAA observou-se a recuperação das plantas de feijão, principalmente pelo surgimento de folhas novas com ausência de sintomas.

Em trabalho de Fernandes et al. (2011) também foi relatado a tolerância do feijoeiro ao halosulfuron, herbicida do mesmo grupo químico do. Porém, os resultados observados na presente pesquisa não podem ser extrapolados para todos herbicidas do mesmo mecanismo de ação, visto que Procópio et al. (2009) demonstraram que o chlorimuron-ethyl, 
imazethapyr e cloransulam-methyl, produtos que também agem inibindo a enzima ALS, foram tóxicos para algumas cultivares de feijoeiro, apesar de registrados para uso na cultura da soja.

A área foliar e a massa da matéria seca total das plantas de feijão não foram afetadas pelas pela aplicação do ethoxysulfuron, independente da dose do herbicida (Figura 2). Observa-se também que a adição do óleo mineral não aumentou a intoxicação do feijoeiro, bem como não interferiu no crescimento da cultura.
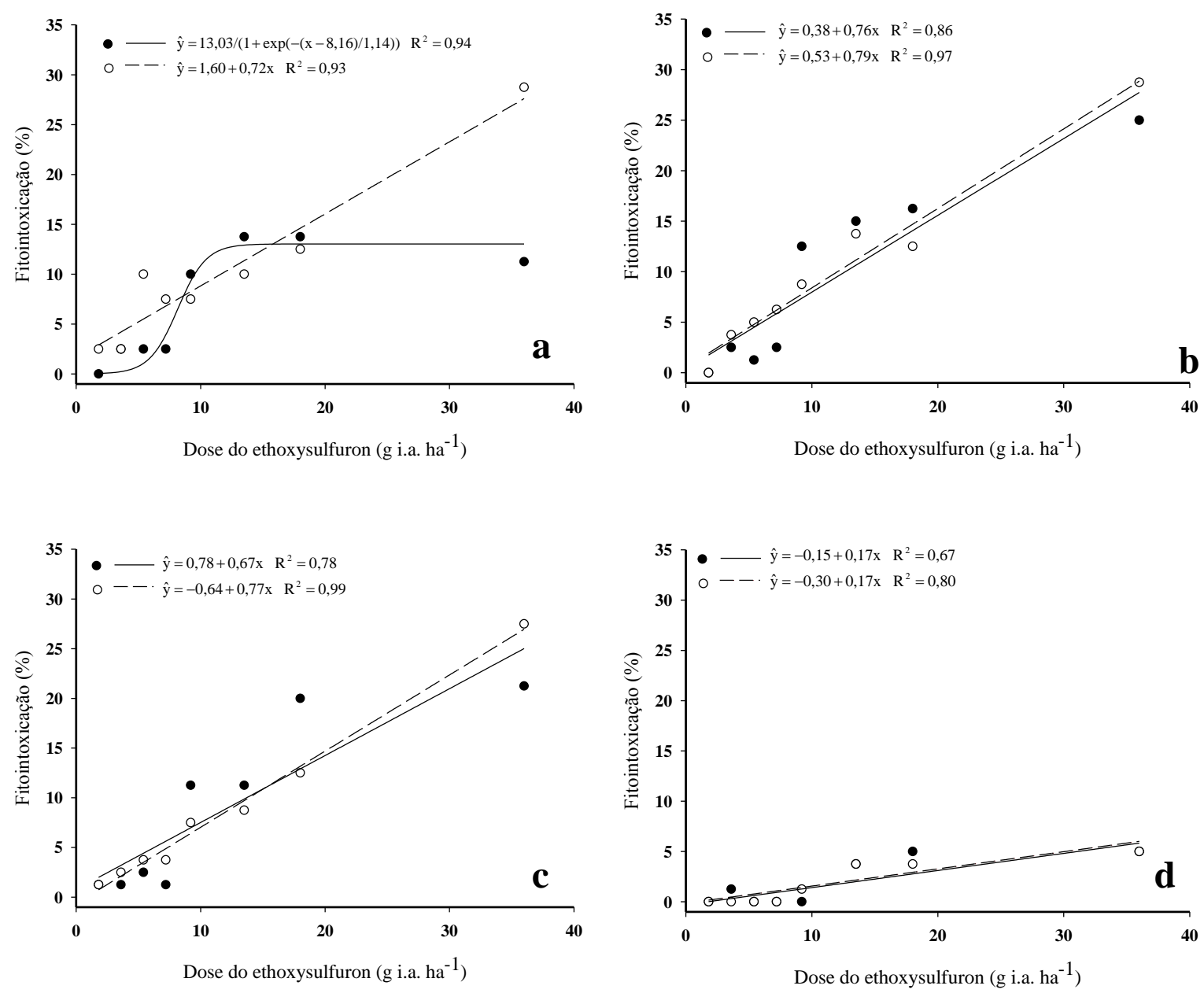

- Herbicida sem óleo mineral

o - - Herbicida com óleo mineral

Figura 1. Fitointoxicação do feijoeiro aos 7 (a), 14 (b), 21 (c) e 28 (d) dias após a aplicação de diferentes doses do ethoxysulfuron. Rio Paranaíba - MG/2014.

Esses resultados indicam a tolerância do feijoeiro ao herbicida ethoxysulfuron para uso em pós-emergência, porém a seletividade só poderá ser confirmada em ensaios de avaliação da produtividade da cultura. Vale ressaltar que as doses testadas nesta pesquisa são menores que as indicadas para as culturas da cana-de-açúcar e arroz irrigado e foram 
determinadas a partir de relatos de produtores sobre a eficiência do produto no controle da soja voluntária em plantios do feijoeiro na região do Alto Paranaíba, Minas Gerais.
Portanto, a seletividade em doses maiores do que a testada pode ser diferente, bem como em outras cultivares de feijão.
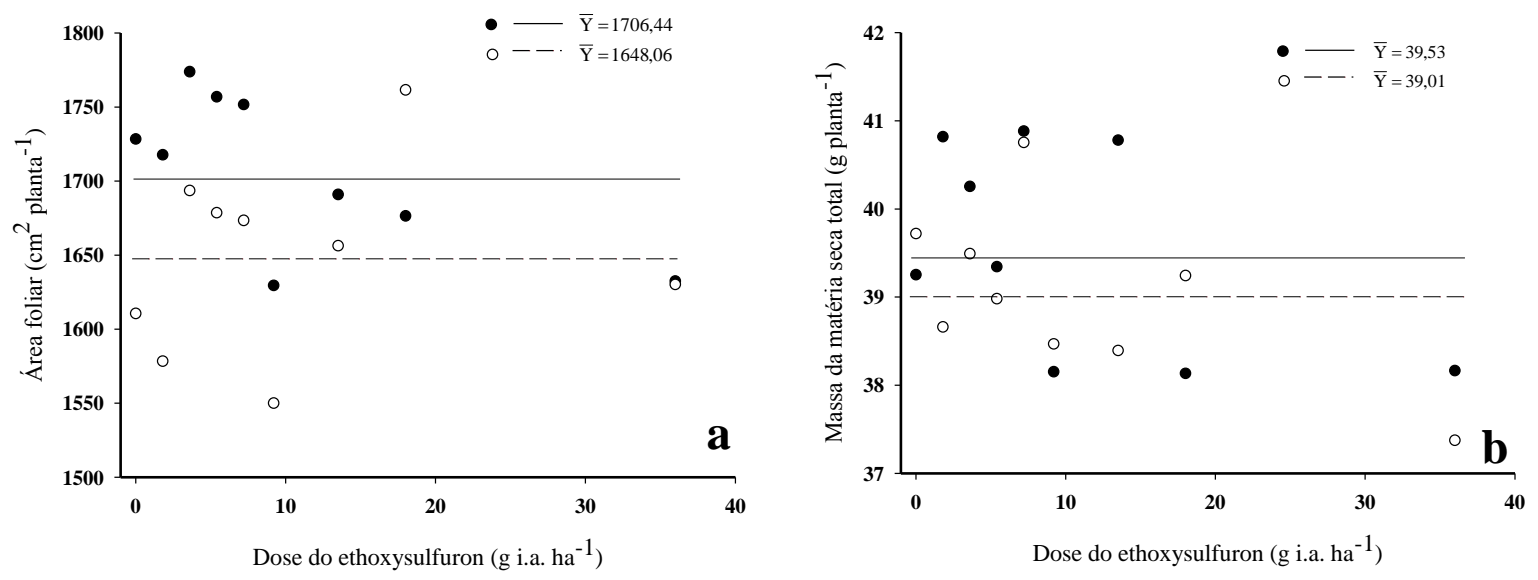

- - Herbicida sem óleo mineral

- - - Herbicida com óleo mineral

Figura 2. Área foliar (a) e massa da matéria seca total (b) do feijoeiro aos 35 dias após a aplicação de diferentes doses do ethoxysulfuron

A soja foi menos tolerante ao ethoxysulfuron em relação ao feijoeiro, com notas altas de fitointoxicação em todas as avaliações realizadas (Figura 3). Os sintomas de fitointoxicação eram mais severos que os visualmente observados para o feijoeiro, sendo notados, além da clorose em folhas novas, cloroses também nas folhas velhas e caule, seguidas de necrose e morte dos tecidos, principalmente nas maiores doses do herbicida. Aos 7 e 14 DAA constatou-se aumento linear da intoxicação das plantas, porém maiores valores foram notados quando adicionada o óleo mineral na calda de aplicação do herbicida. $\mathrm{Na}$ maior dose a fitointoxicação era maior que $60 \%$ no tratamento com óleo mineral (Figura 3 a e $3 b)$.

A aplicação do óleo mineral aumentou a fitointoxicação das plantas de soja, causando, na maior dose, a morte das plantas de soja aos 21 DAA (Figura 3c). Aos 28 DAA observou-se fitointoxicação acima de $60 \%$ das plantas em doses acima de 13,5 g i.a. ha ${ }^{-1}$ e com a adição do óleo (Figura 3d). De maneira geral, nas maiores doses, a fitointoxicação das plantas de soja ao ethoxysulfuron foi em torno de $50 \%$ superiores ao tratamento sem óleo, sendo que o controle total da soja só foi obtido na dose de $36 \mathrm{~g}$ i.a. ha ${ }^{-}$ ${ }^{1}$ com adição de óleo mineral.

Os adjuvantes, como o óleo mineral, geralmente, são recomendados para adição na calda de pulverização de herbicidas aplicados em pós-emergência das plantas. Estes produtos podem aumentar a deposição das gotas nas plantas e a molhabilidade da superfície foliar, devido à redução da tensão superficial e do ângulo de contato da gota, o que consequentemente, aumenta a penetração cuticular e a absorção do ingrediente ativo pela planta (Mendonça et al., 2007). Desta forma, o aumento na deposição de gotas e da absorção pode proporcionar melhores níveis de controle das plantas daninhas e contribuir para a redução da dose do herbicida (Maciel et al., 2010). Costa et al. (2007) relata que a tolerância da cultura ao herbicida também pode ser reduzida pela a ação 
dos adjuvantes, uma vez que, a determinação da seletividade pode ser dependente da dose absorvida do herbicida e da capacidade da planta em metabolizar o ingrediente ativo. Todavia, isso não foi observado neste trabalho, visto que o feijoeiro teve tendência a ser tolerante ao herbicida enquanto a soja foi controlada pela aplicação da maior dose do ethoxysulfuron.
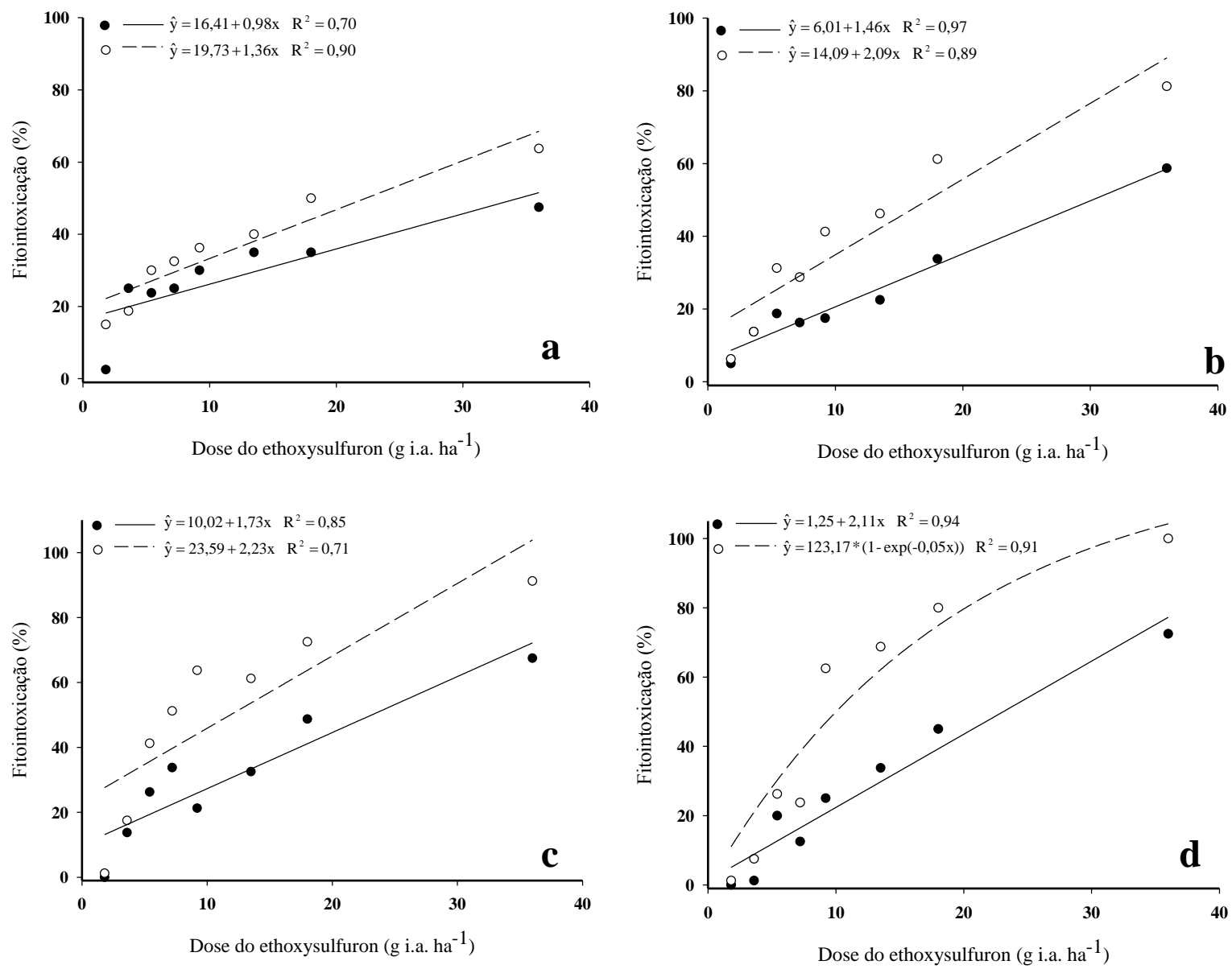

- - Herbicida sem óleo mineral

- - - Herbicida com óleo mineral

Figura 3. Fitointoxicação da soja aos 7 (a), 14 (b), 21 (c) e 28 (d) dias após a aplicação de diferentes doses do ethoxysulfuron. Rio Paranaíba-MG/2014.

A área foliar da soja foi severamente afetada pela aplicação das maiores doses do ethoxysulfuron (Figura 4a). Na presença somente do herbicida foi constatada redução linear e com a adição do óleo mineral redução exponencial da variável. Esses resultados estão relacionados aos sintomas observados, onde as folhas, após cloróticas, destacavam-se das plantas.

A massa da matéria seca das plantas de soja foi exponencialmente reduzida pela aplicação do ethoxysulfuron (Figura 4b). Todavia, a redução foi maior na aplicação do produto com o óleo mineral, ocorrendo à morte das plantas na maior dose do herbicida. Embora 
não tenha matado as plantas, nas doses de 9 , 13,5 e 18 g. i. a. ha ${ }^{-1}$ com óleo mineral houve redução de mais de $80 \%$ no acúmulo de massa da matéria seca da cultura e em condições de campo podem ser suficientes para a supressão da soja, visto que altos índices de fitointoxicação permaneceram 28 DAA.

A tolerância da soja a herbicidas que tem como mecanismo de ação a inibição da enzima ALS varia com o produto utilizado. Alguns herbicidas como diclosulam, cloransulammethyl e imazethapyr pertencentes a grupos químicos diferentes do ethoxysulfuron foram seletivos à soja (Galon et al., 2007; Neto et al., 2009; Correa e Alves, 2009). Todavia, Merotto Jr. et al. (2000) relataram intoxicação de duas cultivares de soja em aplicações no estádio V4 da cultura pelos herbicidas metsulfuron e nicosulfuron corroborando com os resultados observados nesta pesquisa.

Esses resultados confirmam a tendência a diferenças de seletividade do ethoxysulfuron ao feijoeiro e a soja. Apesar de causar intoxicação leve às plantas de feijão, houve a recuperação das plantas e não se constatou alterações no padrão de crescimento. Já o aumento da dose do herbicida incrementa a intoxicação da soja. A adição do óleo mineral proporcionou maior intoxicação da soja voluntária, sendo que o controle total da soja só foi possível com a aplicação de $36 \mathrm{~g}$. i. a. ha ${ }^{-1}$ do herbicida e na presença do óleo mineral.
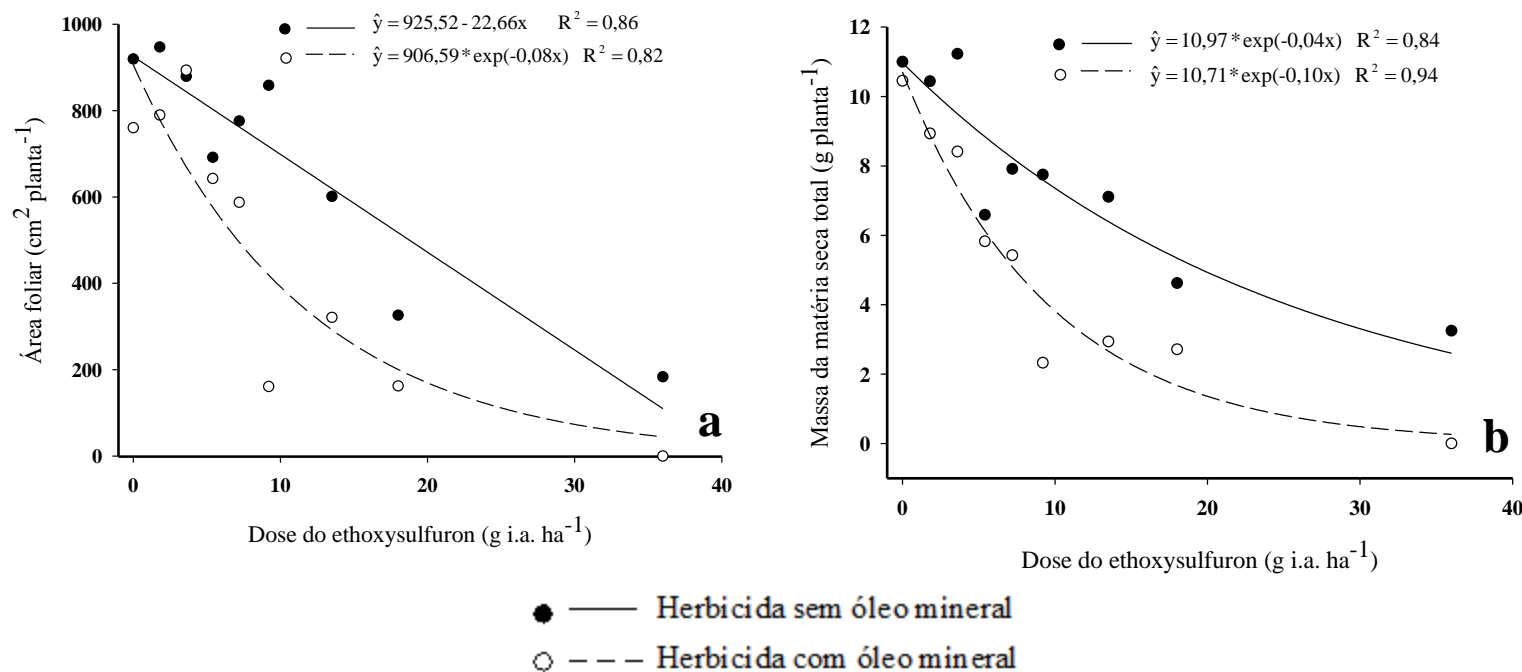

Figura 4. Área foliar (a) e massa da matéria seca total (b) da soja aos 35 dias após a aplicação de diferentes doses do ethoxysulfuron. Rio Paranaíba - MG/2014.

\section{Conclusões}

O uso do ethoxysulfuron causa baixa fitointoxicação e não interfere no crescimento do feijoeiro, independente da adição do óleo mineral. A soja é sensível ao ethoxysulfuron aplicado em pós-emergência, sobretudo quando adicionado o óleo mineral na calda de aplicação. A dose 36 g. i.a. ha ${ }^{-1}$ ethoxysulfuron com o óleo mineral causou a morte das plantas de soja.

\section{Agradecimentos}

Os autores agradecem à Coordenação de Aperfeiçoamento e Pessoal de Nível Superior (CAPES) e à Fundação de Amparo a Pesquisa do Estado de Minas Gerais (FAPEMIG) pelo apoio concedido.

\section{Referências}

BORCHARTT, L. et al. Períodos de interferência de plantas daninhas na cultura do 
feijoeiro-comum (Phaseolus vulgaris L.). Revista Ciência Agronômica, v.42, n.3, p.725734, 2011.

COBUCCI, T.; DI STEFANO, J.G.; KLUTHCOUSKI, J. Manejo de plantas daninhas na cultura do feijoeiro em plantio direto. Santo Antônio de Goiás: EmbrapaCNPAF, 1999. 56 p. (Circular Técnica, 35).

CORREA, M.J.P; ALVES, P.L.C.A. Eficácia de herbicidas aplicados em pós-emergência na cultura da soja convencional e transgênica.

Daninha, v.27, n.spe, p.1035-1046, 2009.

COSTA, N.V. et al. Seletividade de herbicidas aplicados com óleo mineral na cultura da mandioca 'Cascuda'. Revista Brasileira de Herbicidas, v.12, n.3, p.251-259, 2013.

FERNANDES, C.P.C. et al. Tolerância do feijoeiro a herbicidas aplicados na cultura da cana-de-açúcar. Revista Brasileira de Herbicidas, v.10, n.2, p.121-133, 2011

GALON, L. et al. Controle de plantas daninhas e seletividade de herbicidas à cultura da soja, aplicados em dois volumes de calda. Revista Brasileira Agrociência, v.13, n.3, p.325-330, 2007.

INSTITUTO BRASILEIRO DE GEOGRAFIA E ESTATÍSTICA - IBGE. Levantamento Sistemático Produção Agrícola Julho de $2014 . \quad$ Disponível em: < ftp://ftp.ibge.gov.br/Producao_Agricola/Fascic ulo_Indicadores_IBGE/estProdAgr_201407.pd f. Acesso em 28 de jul de 2014.

KOZLOWSKI, L.A. et al. Período crítico de interferência das plantas daninhas na cultura do feijoeiro-comum em sistema de semeadura direta. Planta Daninha, v.20, n.2, p.213-220, 2002.

LEITE, C.R.F.; ALMEIDA, J.C.V.; PRETE, C.E.C. Aspectos fisiológicos, bioquímicos e agronômicos dos herbicidas inibidores da enzima ALS (AHAS). Londrina: Célio Roberto
Ferreira Leite, José Carlos Vieira de Almeida e Cássio Egídio C. Prete, 1998. 68p.

MACIEL, C.D.G. et al. Tensão superficial estática de misturas em tanque de glyphosate+chlorimuron-ethyl isoladas ou associadas com adjuvantes. Planta Daninha, v.28, n.3, p.673- 685, 2010.

MENDONÇA， C.G.; RAETANO， C.G.; MENDONÇA, C.G. Tensão superficial estática de soluções aquosas com óleos minerais e vegetais utilizados na agricultura. Engenharia Agrícola, v.27, n.esp., p.16-23, 2007.

MEROTTO JR., A.M. et al. Tolerância da cultivar de soja Coodetec 201 aos herbicidas inibidores de ALS. Planta Daninha, v.18, n.1, p.93-102, 2000.

NETO, M.E.F. et al. Seletividade de herbicidas pós-emergentes aplicados na soja geneticamente modificada. Planta Daninha, v.27, n.2, p.345-352, 2009.

PROCÓPIO, S.O. et al. Potencial de uso dos herbicidas chlorimuron-ethyl, imazethapyr e cloransulam-methyl na cultura do feijão. Planta Daninha, v.27, n.2, p.327-336, 2009.

TEIXEIRA, I.R. et al. Competição entre feijoeiros e plantas daninhas em função do tipo de crescimento dos cultivares. Planta Daninha, v.27, n.2, p.235-240, 2009. 